\title{
Penerapan Algoritma Boyer Moore Untuk Pencarian Data Member Pada PT. Boenk Cosmetic Manufacture Berbasis Desktop
}

\author{
Masruri Aulia \\ Program Studi Teknik Informatika, STMIK Budi Darma, Medan, Indonesia \\ Email: masruriaulia6@gmail.com
}

\begin{abstract}
Abstrak- PT. Boenk Cosmetic Manufacture merupakan sebuah pabrik yang melakukan perkembangan pada tahun 2013 dalam rangka untuk menghadapi globalisasi, selain itu karena banyaknya minat pasar terhadap produk dipabrik ini sehinggga untuk menjaga eksistensi dan konsistensi pabrik maka pabrik ini dikembangkan. Perusahaan ini telah memenuhi CPKB(Cara Pembuatan Kosmetik yangbaik).PT.Boenk Cosmetic Manufacture setiap bulannya mengalami penambahan member baru berdasarkan berjalannya waktu member akan semakin bertambah. Adapun masalah yang sering dihadapi oleh pegawai PT.Boenk Cosmetic Manufacture semakin tidak terstrukturnya manajemen data member ketika dilakukan pencarian keterangan data member yang mengakibatkan terjadinya kesalahan secara berulang. Dan setiap bulannya sulit untuk mendapatkan hasil pencarian data member yang cepat dan tepat sehingga proses kerja waktu yang banyak Untuk mengatasi permasalah tersebut maka diperlukan sebuah pengembangan sistem dengan menerapkan algoritma string matching guna meminimalisir kesalahan dalam pencarian data member berbasis desktop. Digunakan pada penilitan ini adalah algoritma Boyer Moore. Algoritma boyer moore dipublikasikan pertama kali oleh Robert S. Boyer, dan J. Strother Moore pada tahun 1977. Dengan memulai pencocokan karakter dari pergeseran window tetap dari kiri ke kanan. Jika terjadi kecocokan maka dilakukan perbandingan karakter teks dan karakter pola yang sebelumnya, yaitu dengan sama sama mengurangi indeks dan pola masing masing sebanyak satu. Dengan menggunakan algoritma ini proses pencarian akan lebih cepat dan banyak informasi yang didapat.
\end{abstract}

Kata Kunci: Data Member, Pattern, Algoritma, Boyer Moore, Desktop.

Abstract-PT. Boenk Cosmetic Manufacture is a factory that developed in 2013 in order to deal with globalization, in addition to the large market interest in the products of this factory so as to maintain the factory's existence and consistency, this plant was developed. This company has fulfilled CPKB (How to Make Cosmetics better). PT.Boenk Cosmetic Manufacture every month experiences the addition of new members based on the passage of time members will increase. The problems that are often faced by the employees of PT. Bunk Cosmetic Manufacture increasingly unstructured member data management when searching for member data information that resulted in repeated errors. And every month it is difficult to get fast and precise member data search results so that the work process takes a lot of time. To overcome these problems, it is necessary to develop a system by implementing string matching algorithms to minimize errors in desktop-based member data search. Used in this research is the Boyer Moore algorithm. Boyer Moore's algorithm was first published by Robert S. Boyer, and J. Strother Moore in 1977. By starting character matching from a fixed window shift from left to right. If a match occurs then a comparison of the character of the text and the character of the previous pattern, ie equally reducing the index and pattern of each by one. By using this algorithm the search process will be faster and a lot of information obtained.

Keywords: Member Data, Pattern, Algorithms, Boyer Moore, Desktop.

\section{PENDAHULUAN}

String matching adalah proses pencarian semua kemunculan quary yang selanjutnya disebut pattern kedalam string yang lebih panjang (teks). Pattern dilambangkan dengan $\mathrm{x}=\mathrm{x}[0 . . \mathrm{m}-1]$ dan panjangnya adalah $\mathrm{m}$. Teks dilambangkan dengan y=y [0..n-1] dan panjangnya adalala. String Matching merupakan suatu metode yang digunakan untuk menemukan suatu keakuratan atau hasil dari satu atau beberapa pola teks yang diberikan [1].

PT. Boenk Cosmetic Manufacture merupakan sebuah pabrik yang melakukan perkembangan pada tahun 2013 dalam rangka untuk menghadapi globalisasi, selain itu karena banyaknya minat pasar terhadap produk dipabrik ini sehinggga untuk menjaga eksistensi dan konsistensi pabrik maka pabrik ini dikembangkan. Perusahaan ini telah memenuhi CPKB(Cara Pembuatan Kosmetik yang baik). PT. Boenk Cosmetic Manufacture setiap bulannya mengalami penambahan member baru berdasarkan berjalannya waktu. Member akan semakin bertambah [2]. Masalah yang sering dihadapi oleh pegawai PT. Boenk Cosmetic Manufacture semakin tidak terstrukurnya manajemen data member ketika dilakukan pencarian keterangan data member yang mengakibatkan kesalahan secara berulang dan setiap bulannya sulit untuk mendapatkan hasil pencarian data member yang cepat dan tepat sehingga proses kerja waktu yang banyak.

Algoritma Boyer Moore merupakan salah satu algoritma untuk mencari suatu string di dalam teks, dibuat oleh R.M Boyer dan J.S Moore. Algoritma Boyer Moore melakukan perbandingan dimulai dari kanan ke kiri, tetapi pergeseran window tetap dari kiri ke kanan. Jika terjadi kecocokkan maka dilakukan perbandingan karakter teks dan karakter pola yang sebelumnya, yaitu dengan sama sama mengurangi indeks teks dan pola masing masing sebanyak satu dengan menggunakan algoritma ini [3].

Berdasarkan Penelitian terdaulu yang dilakukan Ramadhansyah (2013) Pelita Informatika Budi Darma, Volume IV, Nomor: 3, yang berjudul "Perancangan Aplikasi Kamus Bahasa Gayo dengan Menggunakan Metode Boyer-Moore". Pada penelitian ini disimpulkan bahwa "Teknik pencarian kosa-kata dengan menggunakan kamus yang dilakukan masyarakat gayo dengan mencari urutan abjad dari suatu kata yang dicari, sehingga proses translasi yang dilakukan memakan waktu yang lama. Dengan digunakannya metode Boyer-Moore dalam pembuatan 
aplikasi kamus bahasa gayo menghasil pencarian translasi kata pada database berjalan dengan lebih cepat dan akurat." [4].

Penelitian yang dilakukan oleh Nelly Astuti Hasibuan (2016) Jurnal Infotek, Volume II, Nomor 3, yang berjudul "Perancangan Aplikasi Kamus Istilah Medis Berbasis Android Dengan Algoritma Boyer-Moore". Pada penelitian ini disimpulkan bahwa "Algoritma boyer-moore dapat diterapkan dalam perancangan aplikasi kamus istilah medis sehingga dapat memudahkan pengguna untuk mencari kata yang ingin diterjemahkan. Dan aplikasi kamus istilah telah selesai dirancang dengan menggunakan software eclipse juno sebagai editor Software Development Kit (SDK) sebagai platform dan telah dapat dijalankan pada perangkat mobile dengan sistem operasi Android 2.3 Gingerbread atau versi di atasnya."[5].

\section{METODE PENELITIAN}

\subsection{String Matching}

String matching adalah algoritma untuk melakukan pencarian semua kemunculan string pendek $\mathrm{P}[0 . . \mathrm{n}-1]$ yang disebut pattern di string yang lebih panjang T[0..m-1] yang disebut teks [2]. Algoritma String Matching merupakan suatu metode yang digunakan untuk menemukan suatu keakuratan atau hasil dari satu atau beberapa pola teks yang diberikan. String string merupakan pokok bahasan yang penting dalam ilmu komputer karena teks merupakan adalah bentuk utama dari pertukaran informasi antar manusia, misalnya pada literatur, karya ilmiah, halaman web dan sebagainya [3].

\subsection{Algoritma Boyer Moore}

Algoritma Boyer Moore adalah salah satu algoritma pencarian string, dipublikasikan oleh Robert S. Boyer, dan J. Strother Moore pada tahun 1977. Algoritma ini dianggap sebagai algoritma yang paling efisien pada aplikasi umum. Tidak seperti algoritma pencarian string yang ditemukan sebelumnya, algoritma Boyer Moore mulai mencocokkan karakter dari sebelah kanan pattern (pola yang di cari). Ide dibalik algoritma ini adalah bahwa dengan memulai pencocokkan karakter dari kanan, dan bukan dari kiri, maka akan lebih banyak informasi yang didapat [6].

Berikut ini adalah Prosedur Pencocokan String Dengan Algoritma Boyer Moore:

1. Buat tabel pergeseran pattern yang dicari $(\mathrm{P})$ dengan pendekatan Match Heuristic $(\mathrm{MH})$ dan Occurence Heuristic $(\mathrm{OH})$, untuk menentukan jumlah pergeseran yang akan dilakukan jika mendapat karakter tidak cocok pada proses pencocokan dengan teks $(\mathrm{T})$.

2. Jika dalam proses pembandingan terjadi ketidakcocokan antara pasangan karakter pada pattern dan karakter teks, pergeseran dilakukan dengan memilih salah satu nilai pergeseran dari dua tabel, dan memiliki nilai pergeseran paling besar dari tabel Match Heuristic dan Occurence Heuristic.

3. Dua kemungkinan penyelesaian dalam melakukan pergeseran pattern, Jika karakter yang tidak cocok, tidak ada pada pattern maka pegeseran adalah sebanyak jumlah karakter pada pattern. maka banyaknya pergeseran bergantung dari nilai pada tabel Match Heuristic dan Occurence Heuristic.

4. Jika karakter pada teks yang sedang dibandingkan cocok dengan karakter pada pattern, maka posisi karakter pada pattern dan teks diturunkan sebanyak 1 posisi, kemudian lanjutkan dengan pencocokan pada posisi tersebut dan seterusnya. Jika kemudian terjadi ketidakcocokan karakter pattern dan teks, maka pilih nilai pergeseran terbesar dari tabel match heuristic dan nilai tabel occurence heuristic.

\section{HASIL DAN PEMBAHASAN}

Masalah yang sering dihadapi oleh Pegawai PT.Boenk Cosmetic Manufacture semakin tidak terstrukurnya manajemen data member ketika dilakukan pencarian keterangan data member yang mengakibatkan kesalahan secara berulang dan setiap bulannya sulit untuk mendapatkan hasil pencarian data member yang cepat dan tepat sehingga proses kerja waktu yang banyak.

Prosedur pencarian data member pada PT.Boenk Cosmetic Manufacture menggunakan algoritma boyer moore dilakukan dengan membandingkan kata kunci yang dicari dengan isi database aplikasi pencarian data member PT.Boenk Cosmetic Manufacture yang dibangun. Kata kunci pada penelitian ini disebut dengan karakter pattern dan isi database aplikasi pencarian data member PT.Boenk Cosmetic Manufacture yang dibangun disebut dengan karakter text. Pencocokan antara karakter pattern dengan karakter text dilakukan dengan pergeseran dari arah kanan ke arah kiri dalam peruses pencocokannya.

Aplikasi pencarian data member PT.Boenk Cosmetic Manufacture dengan menerapkan algoritma boyer moore pada penelitian ini dibangun menggunakan bahasa pemrograman visual basic net 2008 dan database MySQL. Aplikasi Aplikasi pencarian data member PT.Boenk Cosmetic Manufacture dengan menerapkan algoritma boyer moore yang dibangun pada penelitian ini dapat dioperasikan pada laptop atau personal komputer yang didukung sistem operasi windows. 
Implementasi algoritma boyer moore pada penenlitian ini yaitu untuk mendapatkan hasil pencarian data member PT.Boenk Cosmetic Manufacture dengan cepat dan tepat. Salah satu masalah pencarian data member PT.Boenk Cosmetic Manufacture yang akan dilakukan pada penelitian ini adalah pencarian karakter pattern CHU pada text AIDIL CHUN SALON.

Tabel 1. Nilai $\mathrm{OH}$ dan $\mathrm{MH}$ pada pattern penyelesaian :

\begin{tabular}{llll}
\hline Pattern $(\mathrm{P})$ & $\mathrm{C}$ & $\mathrm{H}$ & $\mathrm{U}$ \\
\hline Occurrence Heuristic $(\mathrm{OH})$ & 2 & 1 & 0 \\
MacthHeuristik $(\mathrm{MH})$ & 3 & 3 & 1 \\
\hline
\end{tabular}

Tahapan pencocokan string untuk pencarian karakter pattern CHU pada text AIDIL CHUN SALON adalah sebagai berikut ini :

1. Tahap Pertama

Pada tahap pertama, pencocokan string pattern dimulai dengan deretan string text yang pertama “AID “.

Tabel 2. Processing Tahap Pertama

\begin{tabular}{llllllllllllllll}
\hline 1 & 2 & 3 & 4 & 5 & 6 & 7 & 8 & 9 & 10 & 11 & 12 & 13 & 14 & 15 & 16 \\
\hline $\mathrm{A}$ & $\mathrm{I}$ & $\mathrm{D}$ & $\mathrm{I}$ & $\mathrm{L}$ & & $\mathrm{C}$ & $\mathrm{H}$ & $\mathrm{U}$ & $\mathrm{N}$ & & $\mathrm{S}$ & $\mathrm{A}$ & $\mathrm{L}$ & $\mathrm{O}$ & $\mathrm{N}$ \\
$\mathrm{C}$ & $\mathrm{H}$ & $\mathrm{U}$ & & & & & & & & & & & & &
\end{tabular}

Pada tahap ini karakter U dengan D tidak sama, dan karakter D tidak memiliki kesamaan dengan karakter pattern yang lainnya, sehingga bergeser sebanyak jumlah karakter pattern yaitu 3 langkah.

2. Tahap Kedua

Pada tahap kedua yaitu pencocokan string CHU dengan deretan text "IL ".

Tabel 3. Processing Tahap Kedua

\begin{tabular}{llllllllllllllll}
\hline 1 & 2 & 3 & 4 & 5 & 6 & 7 & 8 & 9 & 10 & 11 & 12 & 13 & 14 & 15 & 16 \\
\hline $\mathrm{A}$ & $\mathrm{I}$ & $\mathrm{D}$ & $\mathrm{I}$ & $\mathrm{L}$ & & $\mathrm{C}$ & $\mathrm{H}$ & $\mathrm{U}$ & $\mathrm{N}$ & & $\mathrm{S}$ & $\mathrm{A}$ & $\mathrm{L}$ & $\mathrm{O}$ & $\mathrm{N}$ \\
& & & $\mathrm{C}$ & $\mathrm{H}$ & $\mathrm{U}$ & & & & & & & & & & \\
\hline
\end{tabular}

Pada tahap ini karakter U dengan (SPASI) tidak sama, dan karakter (SPASI) tidak memiliki kesamaan dengan karakter pattern yang lainnya, sehingga bergeser sebanyak jumlah karakter pattern yaitu 3 langkah.

3. Tahap Ketiga

Pada tahap ketiga dilakukan pencocokan string pattern dengan deretan string text "CHU“.

Tabel 4. Processing Tahap Ketiga

\begin{tabular}{llllllllllllllll}
\hline 1 & 2 & 3 & 4 & 5 & 6 & 7 & 8 & 9 & 10 & 11 & 12 & 13 & 14 & 15 & 16 \\
\hline $\mathrm{A}$ & $\mathrm{I}$ & $\mathrm{D}$ & $\mathrm{I}$ & $\mathrm{L}$ & & $\mathrm{C}$ & $\mathrm{H}$ & $\mathrm{U}$ & $\mathrm{N}$ & & $\mathrm{S}$ & $\mathrm{A}$ & $\mathrm{L}$ & $\mathrm{O}$ & $\mathrm{N}$ \\
& & & & & & $\mathrm{C}$ & $\mathrm{H}$ & $\mathrm{U}$ & & & & & & &
\end{tabular}

Pada tahap ini semua karakter pattern sesuai dengan karakter text yang sejajar dengan karakter pattern, sehingga pergeseran karakter pattern berhenti.

Adapun Perancangan sistem pada penelitian ini berfungsi untuk mempermudah programmer membaca alur program yang akan dibangun Menggunakan Activity diagram. Activity diagram merupakan state diagram khusus, dimana sebagian besar state adalah action dan sebagian besar transisi di-trigger oleh selesainya state sebelumnya (internal processing).

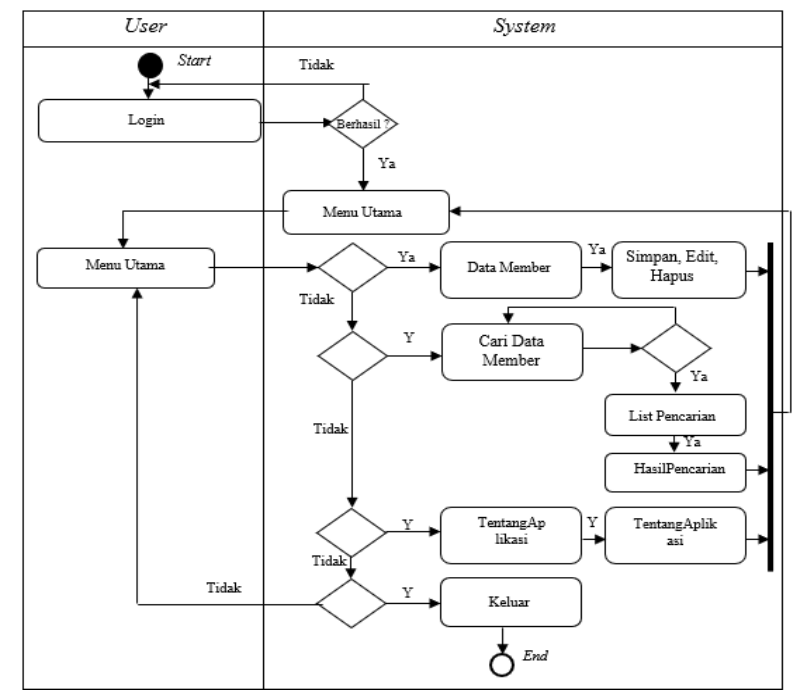

Gambar 1. ActivityDiagram 


\section{KESIMPULAN}

Berdasarkan hasil penelitian yang telah dilakukan penulis dapat diuraikan kesimpulan sebagai berikut ini :

1. Prosedur pencarian data member PT. Boenk Cosmetic Manufacture dilakukan berdasarkan nama member PT. Boenk Cosmetic Manufacture. Supaya tidak terjadinya lagi kesalahan secara berulang dalam pencarian data member.

2. Implementasi algoritma boyer moore untuk mendapatkan hasil pencarian data dan mempermudah penemuan hasil pencarian data member PT. Boenk Cosmetic Manufacture dengan efektif dan efesien.

3. Sistem aplikasi pencarian data member pada PT. Boenk Cosmetic Manufacture dirancang menggunakan visual basic net 2008 dan dapat dioperasikan pada sistem operasi windows.

\section{REFERENCES}

[1] M. \& Handrizal Zarlis, Algoritma \& Pemrograman : Teori dan Pratik dalam Pascal. Medan: USU PRESS, 2008.

[2] Kamara G. H., Visualisasi Beberapa Algoritma Pencocokan String Dengan Java. Bandung: Institut Teknologi Bandung, 2008.

[3] Implementasi Algoritma Pencocokan String pada Aplikasi Pengarsipan Berbasis Web, Journal Informatika, Vol. 3, ISSN:2085-8566, 2012 Ana Ervana \& Asri Pertiwi,.

[4] Dkk., Diana Effendi, "Penerapan String Matching Menggunakan Algoritma Boyer-Moore pada Translator Bahasa Pascal ke C," 2013.

[6] Pencocokan String Berdasarkan Kemiripan Ucapan, Institut Teknologi Bandung, Bandung. 2011. Syaroni dan Munir,.

[7] Ramadhansyah, "Perancangan Aplikasi Kamus Bahasa Gayo dengan Menggunakan Metode Boyer-Moore," vol. Vol. IV, 2013.

[9] Rekayasa Perangkat Lunak Berbasis Objek dengan Metode USDP, Andi, Yogyakarta, 2010. Adi Nugroho,

[10] Wahana Komputer, Membangun Aplikasi Toko dengan Visual Basic 2008. Yogyakarta: Andi, 2009. 